Research Article

\title{
The Influence of Physical and Chemical Reactions on Water Leakage in a Multiarch Tunnel
}

\author{
Jian-Xun Shi $\mathbb{D}^{1,2}$ Zhao-Hui Li, ${ }^{1,2}$ Yong-Qiang He, ${ }^{1,2}$ Guo-Ming Zhang, ${ }^{1,2}$ \\ and Ming-Qiang $\mathrm{Wei}^{{ }^{1,2}}$ \\ ${ }^{1}$ School of Civil Engineering, Northwest Minzu University, Lanzhou 730030, China \\ ${ }^{2}$ State Key Laboratory Base of New Building Materials and Energy-Efficient Building in Gansu Province, \\ Lanzhou 730030, China \\ Correspondence should be addressed to Jian-Xun Shi; sjxnxu@163.com
}

Received 23 July 2020; Revised 30 August 2020; Accepted 11 September 2020; Published 23 September 2020

Academic Editor: Zhushan Shao

Copyright (C) 2020 Jian-Xun Shi et al. This is an open access article distributed under the Creative Commons Attribution License, which permits unrestricted use, distribution, and reproduction in any medium, provided the original work is properly cited.

In many tunnels in China, the groundwater is acidic and carbonated, causing in challenges in the prevention and control of leakages of the existing tunnels and tunnels under construction. Research on tunnel leakage and the physical and chemical effects of water due to water-rock interactions is a trending topic. In addition, there is a big difference between the waterproof and drainage of multiarch tunnels and separate tunnels. In this study, the mechanism of the interaction between the groundwater and the surrounding rock of a multiarch tunnel were analyzed. The relationship between the leakage of a multiarch tunnel and the interaction between the surrounding rocks and groundwater was determined by analyzing the interaction between the chemical components in the groundwater, rocks, and the concrete lining. A mathematical model was established based on the physical and chemical reactions in the rock surrounding the tunnel, and the RNCDX.FOR program was compiled using the simplex Monte Carlo method. The total free energy in the entire system varied significantly, and the value of objective function $(J)$ reflected the trend of the system's spontaneous reaction. As $J$ decreased, the reaction power of the system increased. The more significant the erosion of the rocks was by the groundwater, the more channels were created by the groundwater in the rock, and the more likely the water leakage was.

\section{Introduction}

Water-rock interaction research is one of the leading topics in mechanics and earth sciences. The interaction is referred to as "solid-fluid coupling" in mechanics and "water-rock interaction" in earth sciences. The focus of the former research is on the fundamental laws of mechanical coupling between solids and fluids; the latter is concentrated on the laws of the physicochemical reactions and the physical and chemical characteristics of the rocks and water under hightemperature high-pressure conditions. As an interdisciplinary discipline that integrates civil engineering and geology, geotechnical engineering has focused on rock body hydraulics, i.e., a study of the laws from the perspective of the interaction of the seepage field and stress field. Hellevang et al. [1] provided a guide to model kinetically constrained
$\mathrm{CO}_{2}$-water-rock interactions. Kaszuba et al. [2] demonstrated that the interaction between $\mathrm{CO}_{2}$, water, and rock could lead to the massive dissolution and precipitation of minerals, and numerous techniques existed for obtaining experimental data. Zhao et al. [3] used the discrete element method to analyze the effect of water-rock mechanical interaction and the combination of physical and chemical effects on the deformation of a reservoir bank slope. Recently, the chemical interaction between water and rocks has been increasingly investigated [4-8], especially in the construction of tunnels in China, where the groundwater is acidic and carbonated. These conditions have caused significant challenges in the prevention and control of leakages of existing tunnels and tunnels under construction, as shown in Figure 1. Wang et al. [9] analyzed the mineral origin of carbonate cement, the mechanism of precipitation, the 


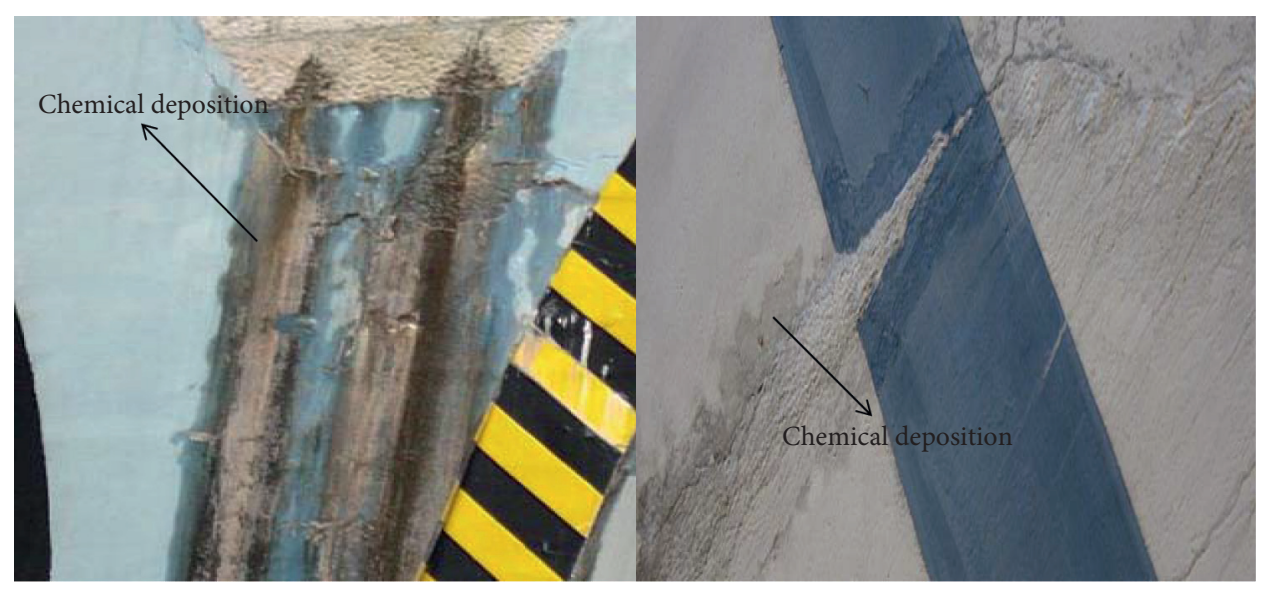

Figure 1: Chemical deposition of seepage water.

evolution and distribution of pore fluids, and the interaction between water and rock and its impact on reservoir quality. At present, there are few random physical and chemical simulation studies on water leakage caused by water-rock interaction in tunnels.

In terms of physical chemistry, the main elements that exhibit chemical reactions in geotechnical engineering include the groundwater and its chemical components, rock formations, organic matter, and materials used in engineering, such as concrete. These elements will interact under certain temperature, pressure, and concentration conditions, produce energy exchange, and generate energy output using input from the environment [10-14]. In addition, the external environment promotes or prevents interactions. Zheng and Liu [5] first used physical and chemical simulations to analyze an aquifer in the surrounding rock of a tunnel, and the model was an optimized linear model. Wang et al. [15] analyzed the mechanism of water-rock interaction inside the aquifer. Many Chinese scholars have investigated the water-rock interaction [16-19]. However, these studies had two limitations. First, most studies used linear programming models, and nonlinearity has not been analyzed in detail. Second, insufficient sample data were used. Most studies did not use sample data from multiple trials, but only from a single trial. The sample data were averaged, and the average value was used for analysis and calculation. Therefore, the mutual influence of the system inside and outside the surrounding rock of the multiarch tunnel and the random changes were ignored, which produced simulation results that did not represent actual conditions.

In this study, the internal energy of the surrounding rock of the tunnel is simulated to determine the degree of erosion and the connectivity of the surrounding rock.

There is a big difference between the waterproof and drainage of multiarch tunnels and separate tunnels. Mao et al. $[20,21]$ used 3D numerical simulation to analyze the water leakage susceptible area of the loess multiarch tunnel. The results show that the water disaster susceptible areas for loess multiarch tunnels during the construction period mainly concentrated in the midpartition, arch springs of the left and right tunnels, and the tunnel face. In this study, the prevention and control of water leakage in a multiarch tunnel is mainly discussed from the perspective of the interaction mechanism between groundwater and surrounding rock.

A mathematical programming model of the physicalchemical conditions of the rock is established. In other words, the chemical reaction inside the surrounding rock of the multiarch tunnel is used as the objective function, and the equilibrium principle, mass conservation law, charge conservation law, and other conditions are used as constraints of the model. After obtaining a model solution, the water-rock interaction inside the surrounding rock of the multiarch tunnel is analyzed to determine the degree of erosion of the surrounding rock caused by the groundwater.

The use of random numbers in the Monte Carlo analysis ensures that the data provide a realistic simulation of actual conditions to reflect the mechanism of water-rock interaction in the surrounding rock of multiarch tunnels. The analysis of the internal chemical reaction of the surrounding rock can provide a theoretical basis for the waterproofing, drainage design, and construction of multiarch tunnels and the prevention and treatment of water leakage.

\section{Mathematical Model of Water-Rock Interaction}

2.1. Mathematical Model. The water-rock interaction can be regarded as an organic connection or a large system of mutual influence [22-25]. In a system with certain pressure, temperature, and concentration conditions, the chemical reaction always proceeds in the direction where the free energy becomes smaller and tends to balance. According to the principle of thermodynamics, the smaller the value of $\Delta G_{f i}$, the stronger the positive reaction trend. Accordingly, take the minimum sum of the free energy changes of each physical and chemical reaction in the groundwater system as the objective function. The constraint conditions are established based on the laws of the conservation of mass, conservation of charge, and neutrality among the chemical components in the groundwater system. The objective 
function and constraints constitute the following mathematical model:

$$
\left\{\begin{array}{l}
P=\min X=\sum_{i=1}^{n} \Delta G_{f i} X_{i}, \\
\sum_{i=1}^{n} a_{i j} X_{i}=d_{j}, \quad(j=1,2, \ldots, m), \\
X_{i}>0,
\end{array}\right.
$$

where $P$ is the free energy change of reaction in the system, $X_{i}$ is the amount of the $i$-th physicochemical reaction, $\mathrm{mmol} / \mathrm{L}$. If $X_{i}>0$, there is a positive reaction inside the system; if $X_{i}<0$, there is a reverse reaction inside the system; if $X_{i}=0$, the system is in equilibrium. $\Delta G_{f i}$ is the free energy change of the $i$-th chemical reaction, $\mathrm{J} \cdot \mathrm{mmol}^{-1}$. $a_{i j}=\alpha_{i k}-\beta_{i k}$, where $\alpha_{i k}$ is the stoichiometric number of the $k$-th component in the corresponding mineral of the $i$-th physicochemical reaction, and $\beta_{i k}$ is the stoichiometric number of the $k$-th component in the corresponding mineral of the generated phase; $d_{j}$ is the concentration difference between the dissolution solution and the initial solution in the $j$-th component; $j=1,2, \ldots, m$, and $m$ is the number of equations with constraint conditions. This mathematical model is of universal significance for describing complex systems of water-rock interactions [25].

\subsection{Stochastic Simulation Solution of the Mathematical Model}

\subsubsection{Random Number Generation}

(1) Uniform distribution: $u(1, w)$

Let the random variable $x$ follow a uniform distribution on $[1, w]$, and its probability density function is

$$
f(x)= \begin{cases}\frac{1}{l-w}, & x \geq 0, \\ 0, & \text { other. }\end{cases}
$$

When random numbers are created using suitable programs, the random numbers are uniformly distributed and statistically independent; they are referred to as pseudo-random numbers.

(2) Normal distribution: $N\left(u, \sigma^{2}\right)$

Let the random variable $x$ follow a normal distribution, and its probability density function is

$$
f(x)=\frac{1}{\sigma \sqrt{2 \pi}} \exp \left[-\frac{(x-u)^{2}}{2 \sigma^{2}}\right] \quad-\infty<x<\infty,
$$

where $u$ is the mean and $\sigma^{2}$ is the variance. The process of generating random numbers is as follows: generate $u_{1}$ from $u(0,1)$ and generate $u_{2}$ from $u(0,1), z=\left[-2 \operatorname{In}\left(\mu_{1}\right)\right]^{(1 / 2)}$ $\sin \left(2 \pi \mu_{1}\right), x=\mu+\sigma_{z}$ returns $x$.

2.2.2. The Monte Carlo Stochastic Simulation Using the Simplex Method. The linear programming method is the most widely used system analysis method. In the early $19^{\text {th }}$ century, the French mathematician Fourier proposed linear programming. In 1974, Dantzig proposed the simplex method to solve linear programming problems. In recent years, the rapid development and popularization of computers have led to extensive use of linear programming methods in industrial and agricultural production, resource allocation, transportation, military, and economic application.

The simplex method is currently the optimum method to solve linear programming problems. Equation (4) is the standard form of linear programming and equation (5) is the constraint condition. The standard form of linear programming not only requires the decision variable $x_{j}$ and the constant $b_{j}$ to be nonnegative but also requires that all constraints are defined as equations. The objective function can be maximized or minimized. The linear programming method is used to simulate the random physical and chemical reactions of the surrounding rock of the tunnel due to water-rock interaction.

Objective function $: \max (\min ) Z=c_{1} x_{1}+c_{2} x_{2} \cdots+c_{n} x_{n}$.

Constraint condition:

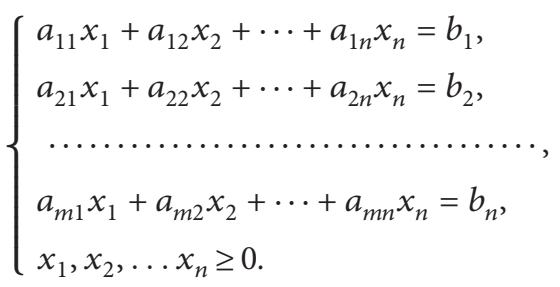

The Monte Carlo method or random simulation method is based on random numbers. The Monte Carlo method was developed in the 1940s. As early as the $17^{\text {th }}$ century, people knew that the probability of an event was determined by the frequency of the event. In the $19^{\text {th }}$ century, people used a needle throwing test to determine pi. The emergence of electronic computers in the 1940s and the subsequent development of high-speed electronic computers in recent years have made it possible to simulate extensive experiments and rapidly perform mathematical calculations. For example, consider a square with a side length of 1 on a plane and an irregularly shaped figure inside; the problem is to find the area of the irregular figure. The Monte Carlo method uses randomization to solve this problem. $N$ points are randomly created in the square, and $M$ points fall within the figure; the area of the figure is approximately $(M / N)$. The Monte Carlo method can be used to deal with the "curse of dimensionality," because the computational complexity of this method does not depend on the dimensionality. Problems that were previously impossible to solve can be solved using the Monte Carlo method. Scientists have proposed many so-called "variance reduction" techniques to increase the efficiency of the method. The Monte Carlo method differs considerably from general calculation methods. The latter is not well suited to solve problems with multiple dimensions or complex factors, whereas the Monte Carlo method is appropriate for such problems. Therefore, the Monte Carlo method 
has been rapidly developed since it was developed and has become an indispensable and important part of computational mathematics.

Each $b_{j}$ in the Monte Carlo system is a random variable. According to the linear programming model, the internal $b_{j}$ implementation is always true. In this way, we randomly extract a $\left[b_{1}^{\prime}, b_{2}^{\prime}, \ldots, b_{m}^{\prime}\right]$ corresponding to $b_{j}$ from the random numbers and use the simplex method to find a set of solutions to $X_{i}^{\prime}=\left[x_{1}^{\prime}, x_{2}^{\prime}, \ldots, x_{n}^{\prime}\right]_{I}$ using equation (1). By analogy, this step is repeated to produce $N$ sets of solutions until $N$ tends to infinity. When all the physical quantities in the system have been described, the characteristics of the physical quantities in the system and the distribution are obtained.

Equation (6) is the definition of the mean value and equation (7) is the definition of the standard deviation:

$$
\begin{aligned}
& \mu=\frac{1}{N} \sum_{i=1}^{N} X_{i} \\
& \sigma=\left[\frac{1}{N-1} \sum_{i=1}^{N}\left(X_{i}-\mu\right)^{2}\right]^{(1 / 2)} .
\end{aligned}
$$

The Monte Carlo method is implemented and a program is written (RNDDX.FOR) for use in the subsequent case study.

\section{Case Study}

3.1. Hydrogeological and Topographic Features in the Tunnel Site Area. The exit of the multiarch tunnel is located on the east side of the downslope of low- and midelevation mountains. The slope is covered with gravel and soil layers and consists of strongly weakly weathered marl and limestone. The gravel soil layer has a maximum thickness of $2.80 \mathrm{~m}$, the thickness of the strongly weathered marl is $1.10 \sim 9.20 \mathrm{~m}$, and the exposed thickness of the weakly weathered marl and limestone is $22.94 \sim 37.38 \mathrm{~m}$. The natural slope of the hillside is $30-40^{\circ}$, the azimuth angle of the free slope of the hillside is $162^{\circ}$, and the slope oblique to the course is about $75^{\circ}$. The occurrence of bedrock is $5^{\circ} \angle 30^{\circ}$, and the gravel soil cover at the entrance is thin $(0.60 \sim 2.80 \mathrm{~m})$. The weathered fissures of the underlying bedrock are well developed, and the rock mass is highly fragmented, showing a fragmented-fissured block structure with poor integrity. The vertical slope velocity of the surrounding rock is $V_{P}=380-1800 \mathrm{~m} / \mathrm{s}$, and the surrounding rock is classified as grade $V$. The conditions for the formation of caves are poor, and the surrounding rock is prone to collapse.

The gravel soil is above the groundwater level and has strong water permeability. Karst water occurs about $500 \mathrm{~m}$ from the cave entrance, and the water volume is large. Due to a large amount of water during the construction, grouting was used as an antiseepage curtain to facilitate construction. However, after one year of operation of the tunnel, significant water leakage occurred, especially at a distance of $500 \mathrm{~m}$ from the entrance of the tunnel. The field data indicated that the $\mathrm{pH}$ value at a distance of $1000 \mathrm{~m}$ from the cave entrance was low, and the water had high concentrations of dissolved $\mathrm{CO}_{2}$. The bedrock is quartz sandstone containing $10 \%$ shale, and the dominant minerals are mica, quartz, a small amount of pyrophyllite, kaolinite, and montmorillonite. Part of the bedrock is carbon shale, with an organic matter content of $4 \%$ to $8 \%[26,27]$. The rocks are highly broken. Due to the long-term immersion in the groundwater and resulting corrosion, some rocks have softened. The field investigation also found that the groundwater had eroded the antiseepage curtain due to cement hydrates in the groundwater, indicating that the chemical components in the groundwater and rock had interacted with the concrete.

Under certain conditions, the water-rock interaction in the area surrounding the tunnel can cause different materials in the surrounding rock to undergo chemical reactions, as shown in Table 1 . The physicochemical reactions in the system are mutually reinforcing, and one reaction will promote another reaction, thus forming a reaction chain of the entire system. Over time, the physicochemical reactions continue, and a groundwater channel is formed and is being continuously connected and unblocked, increasing the water leakage in the tunnel. Depending on the interaction between the components in the surrounding rock, the groundwater components, the organic substances, the components of the concrete grouting curtain, the free energy produced by the reactants and products during the processes determine the reactant's standard free energy change $\left(\Delta G_{f}\right)$.

The monitoring data of the groundwater and surrounding rock in the tunnel and the drainage holes created during construction indicate that the groundwater behind the grouting curtain is the dominant source of recharge. Thus, the groundwater is the initial liquid in the tunnel area, and the discharge liquid of the drainage holes is the dissolution liquid. The chemical composition and the differences between the initial liquid and the dissolution liquid are shown in Table 2. Both variables follow a normal distribution. The difference between the two can be expressed by statistical parameters. The mean of the difference equals the mean of the dissolution solution minus the mean value of the initial solution. The variance of the difference is the square root of the sum of squares of the variance of the dissolution solution and the initial solution; it follows a normal distribution. Four drainage holes are selected as examples for the analysis, namely hole 1 , hole 2 , hole 3 , and hole 4 (Table 2).

3.2. The Establishment of the Mathematical Model. According to the physicochemical reactions and the free energy changes (Table 1) and the random samples of the difference between the initial solution and the dissolution solution of the components in Table 2, the following model is established: 
Table 1: Physicochemical reactions and free energy change $\left(\Delta G_{f}\right)$ of the water-rock system.

\begin{tabular}{|c|c|c|c|c|}
\hline Number & Reaction volume & Reactant & Physicochemical reaction & $\Delta G_{f}\left(\mathrm{~J} \cdot \mathrm{mmol}^{-1}\right)$ \\
\hline 1 & $X_{1}$ & Soda feldspar & $\begin{array}{l}\mathrm{NaAlSi}_{3} \mathrm{O}_{8}+\mathrm{CO} 2+5.5 \mathrm{H}_{2} \mathrm{O} \longrightarrow 0.5 \mathrm{NaAlSi}_{3} \\
\quad(\mathrm{OH})_{4}+\mathrm{Na}^{+}+2 \mathrm{H}_{4} \mathrm{SiO}_{4}+\mathrm{HCO}_{3-}\end{array}$ & 79.97 \\
\hline 2 & $X_{2}$ & $\begin{array}{l}\text { Calcareous } \\
\text { spar }\end{array}$ & $\mathrm{CaCO}_{3}+\mathrm{CO}_{2}+\mathrm{H}_{2} \mathrm{O} \longrightarrow \mathrm{Ca}^{2+}+\mathrm{HCO}_{3-}$ & 27.66 \\
\hline 3 & $X_{3}$ & $\mathrm{Ca}(\mathrm{OH})_{2}$ & $\mathrm{Ca}(\mathrm{OH})_{2}(\mathrm{~s})+\mathrm{CO}_{2} \longrightarrow \mathrm{Ca}^{2+}+2 \mathrm{HCO}_{3-}$ & -56.77 \\
\hline 4 & $X_{4}$ & $\begin{array}{l}\text { Organic } \\
\text { matter }\end{array}$ & $\mathrm{CH}_{2} \mathrm{O}+\mathrm{O}_{2} \longrightarrow \mathrm{CO}_{2}+\mathrm{H}_{2} \mathrm{O}$ & -405.78 \\
\hline 5 & $X_{5}$ & $\mathrm{CO}_{2}$ & $\mathrm{CO}_{2}+\mathrm{H}_{2} \mathrm{O} \longrightarrow \mathrm{H}++\mathrm{HCO}_{3-}$ & 38.9 \\
\hline 6 & $X_{6}$ & $\mathrm{HCO}_{3-}$ & $\mathrm{H}^{+}+\mathrm{HCO}_{3-} \longrightarrow \mathrm{CO}_{2}+\mathrm{H}_{2} \mathrm{O}$ & -38.9 \\
\hline 7 & $X_{7}$ & Maria glass & $\begin{array}{c}\mathrm{KMg}_{3} \mathrm{AlSi}_{3} \mathrm{O}_{10}(\mathrm{OH})_{2}+7 \mathrm{H}^{+}+0.5 \mathrm{H}_{2} \mathrm{O} \longrightarrow 0.5 \mathrm{Al}_{2} \mathrm{Si}_{2} \mathrm{O}_{5} \\
(\mathrm{OH})_{4}+\mathrm{K}^{+}+3 \mathrm{Mg}_{2}++2 \mathrm{H}_{4} \mathrm{SiO}_{4}\end{array}$ & 348.94 \\
\hline 8 & $X_{8}$ & $\mathrm{Mg}(\mathrm{OH}) 2$ & $\mathrm{Mg}(\mathrm{OH})_{2}(\mathrm{~s})+\mathrm{CO}_{2} \stackrel{\mathrm{O}}{\longrightarrow} \mathrm{Mg}^{2+}+2 \mathrm{HCO}_{3-}$ & -53.24 \\
\hline 9 & $X_{9}$ & $\mathrm{Ca}^{2+}$ & $\mathrm{Ca}^{2+}+\mathrm{Na}(\mathrm{s}) \longrightarrow \mathrm{Na}^{+}+\mathrm{Ca}(\mathrm{s})$ & 30.74 \\
\hline 10 & $X_{10}$ & $\mathrm{Mg}^{2+}$ & $\mathrm{Mg}^{2+}+2 \mathrm{Na}(\mathrm{s}) \longrightarrow \mathrm{Na}^{+}+\mathrm{Mg}^{(\mathrm{s})}$ & -70.01 \\
\hline
\end{tabular}

TABLE 2: Differences in the ion contents between the initial solution and dissolution solution.

\begin{tabular}{lccccccccc}
\hline \multirow{2}{*}{ Hole number } & \multirow{2}{*}{ Statistics } & \multicolumn{2}{c}{ Cation content $/\left(\mathrm{mmol} \cdot \mathrm{L}^{-1}\right)$} & \multicolumn{3}{c}{ Anion content $/\left(\mathrm{mmol} \cdot \mathrm{L}^{-1}\right)$} & \multirow{2}{*}{$\mathrm{Erosion} \mathrm{CO}_{2} /\left(\mathrm{mmol} \cdot \mathrm{L}^{-1}\right)$} \\
& & $\mathrm{Na}^{+}+\mathrm{K}^{+}$ & $\mathrm{Ca}^{2+}$ & $\mathrm{Mg}^{2+}$ & $\mathrm{SO}_{4}^{2}$ & $\mathrm{HCO}_{3-}$ & $\mathrm{Cl}^{-}$ & \\
\multirow{2}{*}{ Hole 1 } & Mean value & 0.061 & 0.029 & 0.0818 & -0.0005 & 0.281 & 0.0135 & 0.306 \\
& Mean square error & 0.1259 & 0.0935 & 0.0495 & 0.0491 & 0.2317 & 0.0255 & 0.145 \\
\multirow{2}{*}{ Hole 2 } & Mean value & 0.071 & -0.131 & 0.0045 & -0.0117 & -0.127 & 0.0075 & 0.68 \\
& Mean square error & 0.1425 & 0.0685 & 0.0366 & 0.0521 & 0.1564 & 0.0237 & 0.199 \\
\multirow{2}{*}{ Hole 3 } & Mean value & 0.066 & -0.006 & -0.0017 & -0.0192 & 0.09 & 0.0085 & 0.304 \\
& Mean square error & 0.1371 & 0.0567 & 0.0354 & 0.045 & 0.1472 & 0.0232 & 0.115 \\
\multirow{2}{*}{ Hole 4 } & Mean value & 0.14 & -0.046 & 0.0758 & 0.001 & 0.222 & 0.0075 & 0.623 \\
& Mean square error & 0.2163 & 0.061 & 0.0426 & 0.0541 & 0.1298 & 0.0238 & & 0.161 \\
\hline
\end{tabular}

$$
\begin{aligned}
J= & \min (X)=79.97 X_{1}+23.66 X_{2}-56.77 X_{3} \\
& -405.78 X_{4}+38.9 X_{5}-38.9 X_{6} \\
& +348.94 X_{7}-53.24 X_{8}+30.74 X_{9}-70.01 X_{10} .
\end{aligned}
$$

Constraint equations:

$$
\left\{\begin{array}{l}
X_{2}+X_{3}-X_{9}=\Delta m \mathrm{Ca}^{2+} \\
3 X_{7}-X_{8}-X_{10}=\Delta m \mathrm{Mg}^{2+} \\
X_{1}+X_{7}-2 X_{9}+2 X_{10}=\Delta m \mathrm{Na}^{+} \\
X_{1}+2 X_{2}+2 X_{3}+X_{5}+X_{6}=\Delta m \mathrm{Na}^{+} \\
-X_{1}-2 X_{2}-2 X_{3}+X_{4}-X_{5}+X_{6}-X_{8}=\Delta m \mathrm{CO}_{2}
\end{array}\right.
$$

where $X_{1} \sim X_{10}$ is the number of millimoles of reactants participating in the reaction per liter of groundwater and $\Delta m$ is the difference between the dissolution liquid and the initial liquid content, $\mathrm{mmol} / \mathrm{L}$.

The reaction amounts of the different components are obtained by solving equations (8) and (9).

In the processing of random numbers, some random numbers may not conform to the principles of equilibrium, the conservation of mass, the conservation of charge, and the principle of minimum energy, resulting in a mathematical model with no solution. In the calculation analysis, these random numbers are removed, and the Monte Carlo principle is used to obtain the characteristic value of the reaction amount of each water-rock interaction.

3.3. Mathematical Model Solution. Studies have shown that the number of simulations is crucial in the simulation of Monte Carlo random numbers and affects not only the rationality of the simulation results but also the accuracy of the simulation. Therefore, we tested different numbers of simulations and considered the calculation time and other factors. Ultimately, 1000 simulations were deemed reasonable and met the accuracy requirements. The results of the random simulation of the state of the water-rock interaction system are shown in Table 3.

\section{Results and Discussion}

The results show that the reaction amounts $X_{1} \sim X_{2}$ in Table 3 are zero, indicating that the reaction of albite and calcite did not occur, i.e., $\mathrm{NaAlSi}_{3} \mathrm{O}_{8}+\mathrm{CO}_{2}+5.5 \mathrm{H}_{2} \mathrm{O}$ $\longrightarrow 0.5 \mathrm{NaAlSi}_{3}(\mathrm{OH})_{4}+\mathrm{Na}^{+}+2 \mathrm{H}_{4} \mathrm{SiO}_{4}+\mathrm{HCO}_{3}{ }^{-}, \mathrm{CaCO}_{3}+$ $\mathrm{CO}_{2}+\mathrm{H}_{2} \mathrm{O} \longrightarrow \mathrm{Ca}^{2+}+\mathrm{HCO}_{3}{ }^{-}$. However, this is not the case. The model of the water-rock interaction does not reflect this type of chemical reaction process but only reflects the direction of the chemical reaction of the entire water-rock 
TABLE 3: Random simulation results of the state of the water-rock interaction system.

\begin{tabular}{|c|c|c|c|c|c|c|c|c|c|c|c|}
\hline \multirow{2}{*}{ Hole number } & \multirow{2}{*}{ Statistics } & \multicolumn{9}{|c|}{ Reaction volume $\left(\mathrm{mmol} \cdot \mathrm{L}^{-1}\right)$} & \multirow{2}{*}{ Objective function/J } \\
\hline & & $X_{1} \sim X_{2}$ & $X_{3}$ & $X_{4}$ & $X_{5}$ & $X_{6}$ & $X_{7}$ & $X_{8}$ & $X_{9}$ & $X_{10}$ & \\
\hline \multirow{3}{*}{ Hole 1} & Mean value $(\mathrm{XM}) /\left(\mathrm{mmol} \cdot \mathrm{L}^{-1}\right)$ & 0 & 0.142 & 0.59 & 0.149 & 0.083 & 0.031 & 0.036 & 0.062 & 0.002 & -234.238 \\
\hline & Mean square error (STD) & 0 & 0.082 & 0.281 & 0.201 & 0.152 & 0.021 & 0.027 & 0.043 & 0.004 & 103.27 \\
\hline & Coefficient of variation (Cv) & 0 & 0.577 & 0.476 & 1.349 & 1.831 & 0.677 & 0.75 & 0.694 & 2 & 0.442 \\
\hline \multirow{3}{*}{ Hole 2} & Mean value $(\mathrm{XM}) /\left(\mathrm{mmol} \cdot \mathrm{L}^{-1}\right)$ & 0 & 0.059 & 0.608 & 0.01 & 0.301 & 0.006 & 0.055 & 0.11 & 0.006 & -259.258 \\
\hline & Mean square error (STD) & 0 & 0.054 & 0.259 & 0.041 & 0.209 & 0.008 & 0.025 & 0.051 & 0.02 & 99.233 \\
\hline & Coefficient of variation (Cv) & 0 & 0.915 & 0.426 & 4.1 & 0.694 & 1.33 & 0.455 & 0.464 & 3.33 & 0.383 \\
\hline \multirow{3}{*}{ Hole 3} & Mean value $(\mathrm{XM}) /\left(\mathrm{mmol} \cdot \mathrm{L}^{-1}\right)$ & 0 & 0.089 & 0.393 & 0.039 & 0.122 & 0.004 & 0.036 & 0.071 & 0.017 & -167.281 \\
\hline & Mean square error (STD) & 0 & 0.062 & 0.182 & 0.068 & 0.15 & 0.01 & 0.023 & 0.046 & 0.021 & 73.83 \\
\hline & Coefficient of variation (Cv) & 0 & 0.7 & 0.463 & 1.74 & 1.23 & 2.5 & 0.64 & 0.648 & 1.235 & 0.441 \\
\hline \multirow{3}{*}{ Hole 4} & Mean value $(\mathrm{XM}) /\left(\mathrm{mmol} \cdot \mathrm{L}^{-1}\right)$ & 0 & 0.099 & 0.853 & 0.091 & 0.086 & 0.031 & 0.067 & 0.134 & 0.001 & -340.257 \\
\hline & Mean square error (STD) & 0 & 0.08 & 0.199 & 0.091 & 0.143 & 0.021 & 0.037 & 0.074 & 0.005 & 93.643 \\
\hline & Coefficient of variation $(\mathrm{Cv})$ & 0 & 0.808 & 0.23 & 1 & 1.662 & 0.677 & 0.552 & 0.552 & 5 & 0.275 \\
\hline
\end{tabular}

system from the initial state to the final state. In other words, the spontaneous reaction is still in equilibrium. Therefore, the zero reaction amounts of albite and calcite does not mean that they did not participate in the reaction, but the dissolved amount and precipitation amount of these two minerals are equal, i.e., they offset each other. No. 2 in Table 1 indicates that the surrounding rock of the tunnel is in a process of relatively balanced dissolution and sedimentation. This result is consistent with the fact that white precipitate was observed on the secondary lining in the onsite investigation of the drainage hole orifice and the water leakage. In addition, No. 1 in Table 1 was not selected in the calculation. The reason is that in the physical and chemical reactions of No. $9, \mathrm{Ca}^{2+}$, and $\mathrm{Na}^{+}$were exchanged, which hindered the dissolution of albite in groundwater.

The numbers $3,4,5,6,7,8,9$, and 10 in Table 1 indicate that the main components involved in the reaction are $\mathrm{Ca}$ $(\mathrm{OH})_{2}$, organic matter, $\mathrm{CO}_{2}$, and $\mathrm{HCO}_{3}{ }^{-}$. The organic matter (No. 4) is the dominant component in the reaction, indicating that the composition of the rock $1000 \mathrm{~m}$ from the tunnel entrance has an important influence. Organic matter is found in the interlayer, and the reaction is strongly oxidized and is strong at all simulated pore numbers. The result shows that the groundwater at the drainage hole is acidic $(\mathrm{pH}<7.0)$, and the groundwater at the grouting curtain and the water in the drainage hole are even more acidic (such as hole 3 and hole 4). Therefore, carbonic acid erosion by the groundwater occurs. Moreover, the water in the drainage holes contains large amounts of dissolved $\mathrm{CO}_{2}$, which is consistent with field observations.

The reaction number 3 in Table 1 describes the interaction with $\mathrm{Ca}(\mathrm{OH})_{2}$ due to the acid-base balance and organic oxidation. The component $\mathrm{Ca}(\mathrm{OH})_{2}$ in the grouting body of the concrete and curtain is alkaline, and the groundwater is acidic; thus, the system is not in an equilibrium state. In addition, dissolution and precipitation should also be considered, because the attenuation or loss of the waterproofing effect of the curtain body is caused by the loss of cement particles in the body. The durability of the secondary concrete lining will be affected by the precipitation of the cement hydration products in the body. These processes will lead to the failure of the waterproofing and drainage measures of the multiarch tunnel. In the treatment of seepage water, these reactions should be suppressed by chemical grouting.

Equations (4) and (5) in the mathematical model indicate that the total free energy of the system varies significantly. The value of the objective function $(J)$ reflects the trend of the reaction power of the system. As $J$ decreases, the reaction power increases. Therefore, dynamic water-rock interaction occurs about $1000 \mathrm{~m}$ from the entrance of the cave. The variance value is also relatively large, which can cause a spontaneous reaction in the system.

\section{Conclusion}

(1) The leakage of the multiarch tunnel was significantly affected by the groundwater. The chemicals in the groundwater interacted with the surrounding rocks, concrete, and other components. The groundwater was acidic, resulting in carbonate erosion and the subsequent leakage of the multiarch tunnel.

(2) A physical-chemical model of the water-rock interaction was established by considering the mechanism of the interactions between the rock surrounding the tunnel, the concrete, and the groundwater. The Monte Carlo method was used to take into account the multidimensional and complex factors and perform random number simulation. We used trial and error to determine the number of simulations (1000 times). The obtained water-rock interaction system of the multiarch tunnel met the accuracy requirements, and the state of the system and chemical interactions were simulated. The proposed method provides a new approach for the determination of the connectivity of the rock surrounding the multiarch tunnel.

(3) The results indicated that the total free energy in the system varied significantly. The value of $J$ reflected the trend of the spontaneous reaction of the system. As $J$ decreased, the reaction power increased. 
Therefore, dynamic water-rock interaction occurred about $1000 \mathrm{~m}$ from the opening of the cave. The variance value was also relatively large, indicating the occurrence of a spontaneous reaction in the system. As a result, the connectivity of the surrounding rock of the multiarch tunnel was increased, resulting in continuous leakage.

\section{Notations}

\begin{tabular}{|c|c|}
\hline$P:$ & Free energy change of reaction in the system \\
\hline$X_{i}:$ & Amount of the $i$-th physicochemical reaction \\
\hline$a_{i j}:$ & $\begin{array}{l}\text { Stoichiometric coefficient of the } j \text {-th element in } \\
\text { the } i \text {-th physical and chemical reaction mineral }\end{array}$ \\
\hline$d_{j}:$ & $\begin{array}{l}\text { Concentration difference between the } \\
\text { dissolution solution and the initial solution in } \\
\text { the } j \text {-th component }\end{array}$ \\
\hline$m:$ & Number of equations with constraint conditions \\
\hline$x:$ & Random variable \\
\hline$l, w:$ & $\begin{array}{l}\text { Upper and lower limits of the distribution of the } \\
\text { random variable }\end{array}$ \\
\hline$u:$ & Mean \\
\hline$\sigma^{2}:$ & Variance \\
\hline$b_{j}:$ & Constant \\
\hline$\sigma:$ & Standard deviation \\
\hline$J:$ & Objective function value \\
\hline$X_{1} \sim X_{10}$ & $\begin{array}{l}\text { Number of millimoles of reactants participating } \\
\text { in the reaction per liter of groundwater. }\end{array}$ \\
\hline
\end{tabular}

\section{Data Availability}

The data used in the study are available upon request to the corresponding author.

\section{Conflicts of Interest}

The authors declare that they have no conflicts of interest.

\section{Acknowledgments}

The authors would like to express their gratitude to Tong Haitao and Song Hanzhou for their assistance with the experiments and the use of the data used in this study.

\section{References}

[1] H. Hellevang, V. T. H. Pham, and P. Aagaard, "Kinetic modelling of $\mathrm{CO}_{2}$-water-rock interactions," International Journal of Greenhouse Gas Control, vol. 15, pp. 3-15, 2013.

[2] J. Kaszuba, B. Yardley, and M. Andreani, "5. Experimental perspectives of mineral dissolution and precipitation due to carbon dioxide-water-rock interactions," Geochemistry of Geologic CO2 Sequestration, vol. 77, no. 1, pp. 153-188, 2013.

[3] Z. Zhao, T. Guo, Z. Ning, Z. Dou, F. Dai, and Q. Yang, "Numerical modeling of stability of fractured reservoir bank slopes subjected to water-rock interactions," Rock Mechanics and Rock Engineering, vol. 51, no. 8, pp. 2517-2531, 2017.

[4] H. T. Tong and H. Z. Song, "Water-rock of the system function random hydrogeochemical simulation," Water Scientific Progress, vol. 21, no. 2, pp. 211-215, 2004, in Chinese.
[5] X. L. Zheng and H. J. Liu, "Shandong alumina water system of the environmental geochemical reaction model," The Earth Chemistry, vol. 3, pp. 270-276, 1990, in Chinese.

[6] Y. Chen and M. Gao, "Water-rock interaction model and its application in water-basalt reaction," Journal of Nanjing University, vol. 1, pp. 118-123, 1994, in Chinese.

[7] J. X. Lai, J. L. Qiu, H. B. Fan et al., "Structural safety assessment of existing multiarch tunnel: a case study," Advances in Materials Sciences and Engineering, vol. 2017, Article ID 1697041, 12 pages, 2017.

[8] T. Liu, Y. Xie, Z. H. Feng, Y. Luo, K. Wang, and W. Xu, "Better understanding the failure modes of tunnels excavated in the boulder-cobble mixed strata by distinct element method," Engineering Failure Analysis, vol. 116, Article ID 104712, 2020.

[9] J. Wang, Y. Cao, K. Liu, J. Liu, X. Xue, and Q. Xu, "Pore fluid evolution, distribution and water-rock interactions of carbonate cements in red-bed sandstone reservoirs in the Dongying depression, China," Marine and Petroleum Geology, vol. 72, pp. 279-294, 2016.

[10] J. X. Shi, X. R. Liu, W. Z. Cao, C. Q. Chen, and Y. H. Yang, "Study on the water of leakage diseases caused by frost heave of multiple-arch tunnel," Disaster Advances, vol. 6, no. 2, pp. 20-26, 2013.

[11] T. H. Yang, "Rock failure process permeability properties and stress coupling," Dissertation, Northeastern University, Boston, MA, USA, 2001, in Chinese.

[12] E. M. Kweilin and R. W. Healy, "Numerical investigation of steady liquid water flow in a variably saturated fracture networks," Water Resources, vol. 29, no. 12, pp. 4091-4102, 1993.

[13] Y. Meng and M. L. Lei, "Karst area tunnel gushing water research status and the suggestion," China Karst, vol. 37, no. 4, pp. 287-290, 2003, in Chinese.

[14] K. Wu and Z. Shao, "Visco-elastic analysis on the effect of flexible layer on mechanical behavior of tunnels," International Journal of Applied Mechanics, vol. 11, no. 3, p. 20, 2019.

[15] J. G. Wang, Z. F. Zhou, and R. L. Tang, "The water-rock effect linear programming model and application to cross the los hydropower project as an example," Water Scientific Progress, vol. 10, no. 2, pp. 118-122, 1999, in Chinese.

[16] D. L. Zhu and Q. F. Li, "Forecast method of tunnel yield," Engineering Survey, vol. 38, no. 4, pp. 18-32, 2000, in Chinese.

[17] P. A. Hsieh and S. P. Neuman, "Field determination of the three-dimensional hydraulic conductivity tensor of anisotropic media: 1. theory," Water Resources Research, vol. 21, no. 11, pp. 1655-1665, 1985.

[18] S. S. Xu, H. Lei, C. Li, H. Q. Liu, J. X. Lai, and T. Liu, "Model test on mechanical characteristics of shallow tunnel excavation failure in gully topography," Engineering Failure Analysis, vol. 118, Article ID 104839, 2020.

[19] T. Y. Xu, Z. J. Zhou, R. P. Yan et al., "Real-time monitoring method for layered compaction quality of loess subgrade based on hydraulic compactor reinforcement," Sensors, vol. 20, no. 15, Article ID 4288, 2020.

[20] Z. Mao, X. Wang, N. An, X. Li, and R. Wei, "Water disaster susceptible areas in loess multi-arch tunnel construction under the lateral recharge condition," Ksce Journal of Civil Engineering, vol. 23, no. 10, pp. 4564-4577, 2019.

[21] Z. J. Mao, X. K. Wang, N. An et al., "Water leakage susceptible areas in loess multi-arch tunnel operation under the lateral recharge conditions," Environmental Earth Sciences, vol. 79, no. 15, p. 32, 2020. 
[22] J. Bear, Dynamics of Fluids in Porous Media, Li Jing-Sheng, Chen Chong-Xi Translation, China Architecture \& Building Press, Beijing, China, 1983.

[23] D. S. Vincent, R. E. Williams, and G. L. Bloomsburg, "Groundwater flow patterns in the vicinity of underground openings in unsaturated rock," Journal of Hydrology, vol. 127, no. 1-4, pp. 1-21, 1991.

[24] H. J. Yang and F. G. Li, "Buried deep groundwater treatment technology of long tunnel," Geotechnical Engineering, vol. 3, pp. 343-356, 2005, in Chinese.

[25] Z. F. Zhou and Y. Li, "Complicated rock mass movement of groundwater problems limited analysis," Water Scientific Progress, vol. 3, pp. 102-108, 1997, in Chinese.

[26] J. Wang, W. Li, and Z. Song, "Development and implementation of new triangular finite element based on MGE theory for bi-material analysis," Results in Physics, vol. 13, Article ID 102231, 2019.

[27] J. Wang, Q. Zhang, Z. Song, and Y. Zhang, "Creep properties and damage constitutive model of salt rock under uniaxial compression," International Journal of Damage Mechanics, vol. 29, no. 6, pp. 902-922, 2020. 